(C) [2009] IEEE. Reprinted, with permission, from Xu, Wei; Zhu, Jianguo; Guo, Youguang; Dorrell, David; Li, Yongjian; Wang, Yi. 2009, 'Drive system analysis of a novel plug-in hybrid vehicle', Proceedings - 35th Annual Conference of IEEE Industrial Electronics, 2009. IECON '09., pp. 3717-3722. This material is posted here with permission of the IEEE. Such permission of the IEEE does not in any way imply IEEE endorsement of any of the University of Technology, Sydney's products or services. Internal or personal use of this material is permitted. However, permission to reprint/republish this material for advertising or promotional purposes or for creating new collective works for resale or redistribution must be obtained from the IEEE by writing to pubs-permissions@ieee.org. By choosing to view this document, you agree to all provisions of the copyright laws protecting it. 


\title{
Drive System Analysis of a Novel Plug-in Hybrid Vehicle
}

\author{
Wei Xu, Jianguo Zhu, Youguang Guo, David Dorrell, Yongjian Li, Yi Wang \\ School of Electrical, Mechanical and Mechatronic Systems, University of Technology,Sydney, Australia \\ wxu@eng.uts.edu.au
}

\begin{abstract}
With the rapid increase of population and economy, lots of cities are suffering from heavy consumption of fossil fuels and air pollution caused by the conventional internal combustion engine (ICE) powered vehicles. With great breakthrough in battery technology, plug-in hybrid electric vehicles (PHEVs) jointly powered by electric machines and an ICE are a good choice to reduce the vehicle pollution. In a PHEV, the battery is charged by the grid and the electric machine plays the major role in vehicle drive whereas the ICE is only required to provide extra torque when accelerating and drive the generator when the battery electricity level is low. This paper discusses one novel PHEV drive system with only one electric machine which functions as either a motor or generator at a time and a supercapacitor bank for fast charging and discharging during the regenerative braking and fast acceleration. The propulsive resistance powers in the PHEV have been investigated so as to decide major system parameters according to project requirements. The drive system has been modeled by PSAT software. Many indexes in the PHEV, such as fuel economy, engine efficiency, distance, and acceleration, have been compared with those of traditional car. Furthermore, the PHEV propulsive performance in three typical driving cycles, UDDS, EUDC, and HWFET, have been evaluated in detail.
\end{abstract}

\section{INTRODUCTION}

Most vehicles running on roads today are propelled by internal combustion engines (ICEs). Conventional gasoline and diesel-fueled vehicles possess advantages such as good performance, long driving range, ease in refueling, and lightweight energy source. These advantages have enabled the conventional vehicles to dominate the market. However, conventional vehicles have serious disadvantages in regard to energy sources and environment protection, primarily the very inefficient usage of the petroleum sources and serious air pollution. Fig. 1 shows the $\mathrm{CO}_{2}$ emission proportion in California, where transportation pollution takes up to $41 \%$ [1].

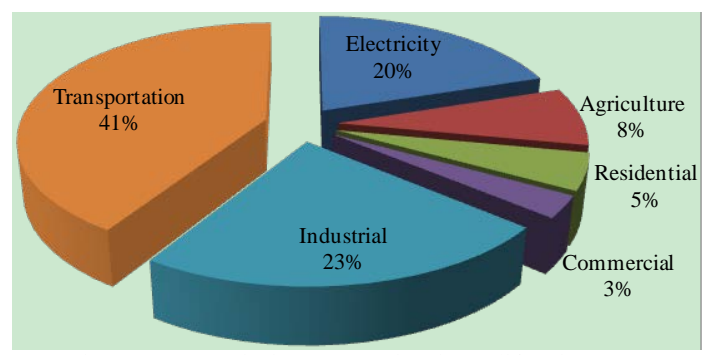

Fig. 1. $\mathrm{CO}_{2}$ emission proportion in California, USA

The electric vehicles (EVs), which have been under development for many years, are considered to be important substitutes of the conventional vehicles. But the acceptability of the EVs in the automobile market has encountered major obstacles. Due to the heavy and bulky batteries on board, the electric vehicles usually have sluggish performance, limited loading capacity, short range, long battery recharging time, and high manufacture cost. Hybrid electric vehicles (HEVs) under development in recent years are considered to be the best tradeoff between conventional and electric vehicles. In a hybrid vehicle, two power plants are available which commonly are an ICE and an electric motor. The inclusion of two power plants provides flexibility to use either the ICE or the motor or both for traction according to the operation characteristics and driving requirement. This configuration increases the potential to optimize the overall drive train operation. It also, however, increases the complexity in the management of the powers supplied by both engine and motor. Therefore, the control strategy of the power plants is a crucial aspect in the development of HEVs.

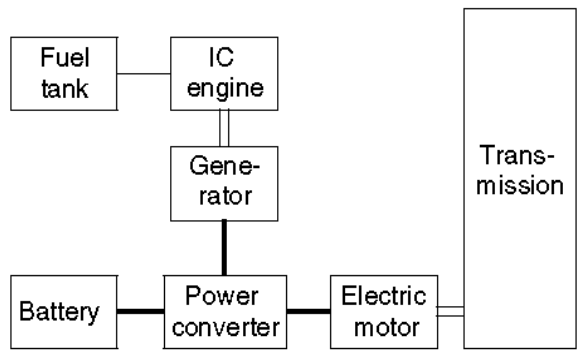

(a)

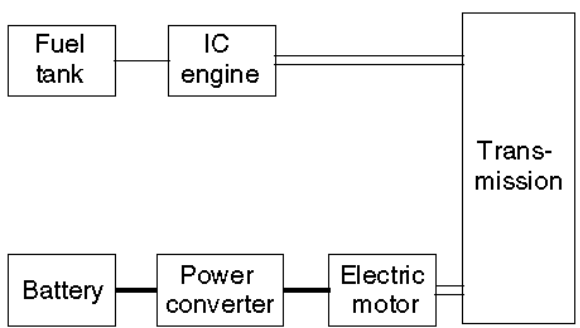

(b)

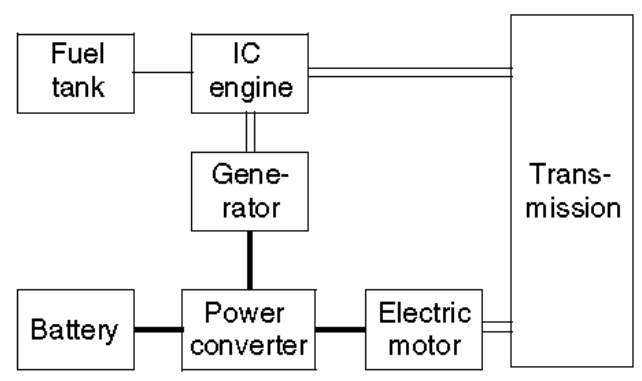

(c)

Fig. 2. Classification of HEVs: (a) Series hybrid; (b) Parallel hybrid; and (c) Series-parallel hybrid 
Battery powered EVs can bring some merits over the ICE cars, such as zero environmental pollution and high energy efficiency. However, its operation range is far less competitive than ICE vehicles because of the low battery power density. HEVs have advantages of both EV and ICE cars, which employ two power sources, a primary unit ICE fuelled by a petrol tank and a supplementary unit of motor and generator fuelled by a battery and/or super-capacitor bank.

In general, the $\mathrm{HEV}$ powertrain configurations can be classified as the series, parallel, and combined parallel-series, as illustrated in Fig. 2 [1]. From the diagram, the series configuration is the simplest in structure, but perhaps the lowest in efficiency for the double energy conversion from the engine to wheels. The parallel system employs the ICE and the electric motor propulsion drive in parallel so that there is direct mechanical propulsion. The parallel-series system incorporates the merits of the series and parallel systems and has high efficiency and compact volume; hence, it is widely used in HEVs.

Fig. 3 shows the structure of the parallel-series system in the Toyota Prius launched in 1997 [2].The wheels are driven by the engine directly and by the electric motor $M$ while the battery is charged through the generator $G$ that is driven by the engine using a power split unit. During regenerative braking, both motor $\mathrm{M}$ and generator $\mathrm{G}$ can be used to charge the battery. The powertrain is designed to well suit the need of an EV that the ICE acts as the primary energy supplying source. One of the most attractive advantages of this powertrain is the electric continuously variable transmission (ECVT) functionality brought by the power split device and Generator $G$ through controlling its speed. The ECVT can keep the engine operating at a fixed speed most time thereby minimizing the fuel consumption and emission. Also, the drive system has various working variations in need of flexible control schemes as developed by Toyota, Honda and Nissan. Due to the reasons mentioned above, the powertrain becomes complicated and requires two electrical machines which finally increase the cost, additional copper and iron losses as well as more friction loss in the mechanical system.

If the battery of an HEV can be charged from the grid, it is called plug-in hybrid electrical vehicles (PHEV). Compared to the HEV, PHEV has a battery with higher capacity, which is the primary power unit while the ICE is the auxiliary one. By now, PHEV has not been commercialized for high cost and un-matured technology in energy management strategy and drive system $[1,3]$.

In this paper, one novel PHEV drive system has been analyzed as illustrated in Fig. 4 [4]. It consists of an energy storage system (grid-chargeable batteries combined with super-capacitors), a power control unit (DC link, DC/DC converters and 2-quadrant inverter/rectifier converters), an electric machine (motor/generator - MG) and an ICE. Only one electrical machine is required in this system, which acts as a motor in normal drive or as a generator when there is regenerative braking or charging of the battery and/or super- capacitor from the ICE. The proposed energy management strategy will be used in the PHEV to ensure that the target driving performance is achieved.

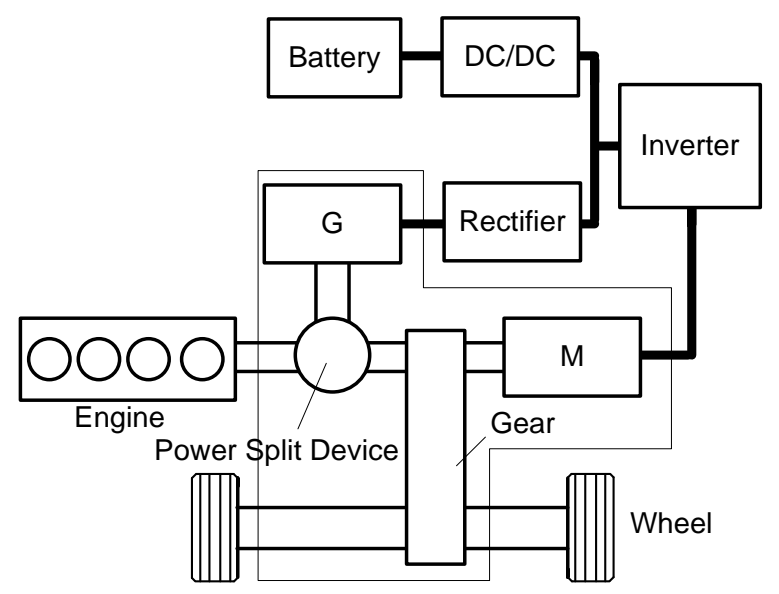

Fig. 3. Toyota hybrid system configuration

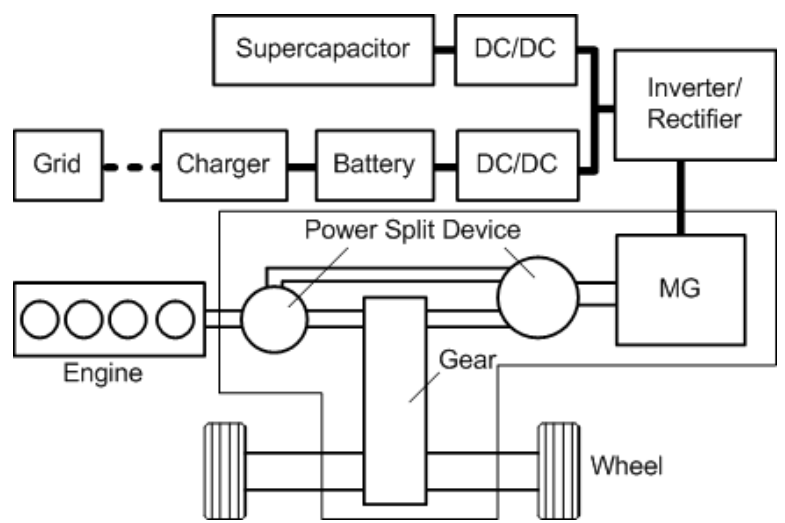

Fig. 4. Proposed novel PHEV system configuration

II. VEHICLE RESISTANCE ANALYSIS

In the PHEV, the vehicle is propelled by both the electric machine and engine, where the traction machine torque and power versus speed curve is very essential as shown in Fig. 4. There are three regions: the constant torque region I (below the base speed), constant power region II (between the base speed and critical speed) and reduced power region III (above the critical speed). In relation to the road speed in Australia, the base speed should be typically about $50 \mathrm{~km} / \mathrm{h}$, and the critical speed $200 \mathrm{~km} / \mathrm{h}$. During acceleration, the power on the driven wheel can be expressed as

$$
P_{t r}=\frac{M_{v}}{2 t_{a}}\left(V_{b}^{2}+V_{f}^{2}\right)+\frac{2}{3} M_{v} g f_{r} V_{f}+\frac{1}{5} \rho_{a} C_{D} A V_{f}^{3}
$$

where $P_{\mathrm{tr}}$ is the traction power for the driven wheels in $\mathrm{w}, V_{\mathrm{b}}$ is the base speed in $\mathrm{m} / \mathrm{s}, V_{\mathrm{f}}$ is the final speed after acceleration in $\mathrm{m} / \mathrm{s}, M_{\mathrm{v}}$ is the vehicle mass in $\mathrm{kg}, g$ is gravity acceleration of $9.81 \mathrm{~m} / \mathrm{s}^{2}, \quad f_{\mathrm{r}}$ is the rolling resistance coefficient, $\rho_{\mathrm{a}}$ is the air mass density of $1.205 \mathrm{~kg} / \mathrm{m}^{3}, C_{\mathrm{D}}$ is the aerodynamic coefficient of the vehicle, and $A$ is the front area in $\mathrm{m}^{2}$ [5].

By (1), the time to accelerate the vehicle is, 


$$
t_{a}=\int_{0}^{V_{f}} \frac{M_{v}}{P_{t} / V-\left(M_{v} g f_{r}+0.5 \rho_{a} C_{D} A V^{2}\right)} \mathrm{d} V
$$

where $t_{\mathrm{a}}$ is the time used to accelerate the car from zero up to the final speed $V_{\mathrm{f}}$.

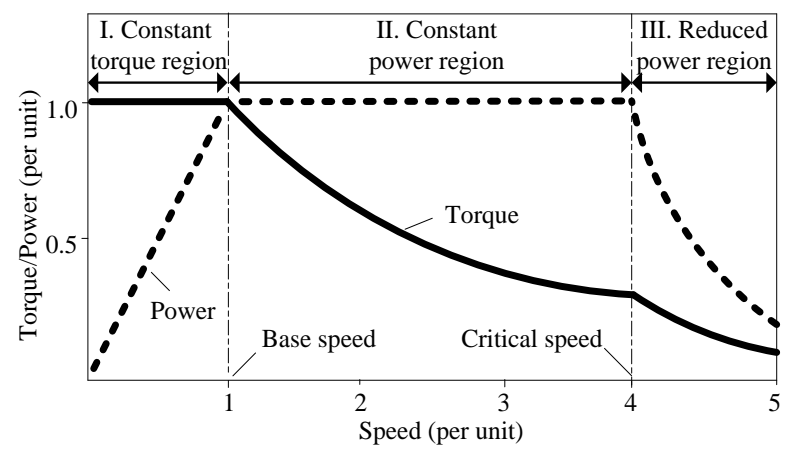

Fig. 5. Torque and power versus speed curves

In order to obtain an analytical solution from (2), let us firstly ignore the rolling resistances and aerodynamic drag, then the approximate form of (2) is

$$
t_{a}=\int_{0}^{V_{b}} \frac{M_{V}}{P_{t r} / V} \mathrm{~d} V+\int_{V_{b}}^{V_{f}} \frac{M_{V}}{P_{t r} / V} \mathrm{~d} V=\frac{M_{V}}{2 P_{t r}}\left(V_{b}^{2}+V_{f}^{2}\right)
$$

where $P_{\text {tr }}$ is the rated tractive power, corresponding to the power in the constant power range in Fig. 5. From (3), $P_{\mathrm{tr}}$ can be gained in one given acceleration time $t_{\mathrm{a}}$ by

$$
P_{t r}=\frac{M_{v}}{2 t_{a}}\left(V_{b}^{2}+V_{f}^{2}\right)
$$

The power $P_{\text {tr }}$ is the only power to accelerate the vehicle kinetic energy, excluding the extra power consumed by rolling resistance and aerodynamic drag. In order to gain the total power, an effective approach is to add the average power depleted by the rolling resistance and aerodynamic drag to the fundamental power, $P_{\mathrm{tr}}$. From (1), the average resistance power, $P_{\text {ra }}$ can be expressed as,

$$
P_{r a}=\frac{1}{t_{a}} \int_{0}^{t_{a}}\left(M_{v} g f_{r} V+0.5 \rho_{a} C_{D} A V^{3}\right) \mathrm{d} t
$$

where $V$ is the function of time during vehicle acceleration, and hence it cannot be analytically solved. From [5], a second order algebraic function may be used to simplify the acceleration time-speed profile by

$$
t=\frac{V^{2}}{V_{f}^{2}} t_{a}
$$

Substituting (6) into (5), the average resistance power, $P_{\text {ra }}$, can be obtained as,

$$
P_{r a}=\frac{2}{3} M_{v} g f_{r} V_{f}+\frac{1}{5} \rho_{a} C_{D} A V_{f}^{3}
$$

Hence, the total power of the traction motor is

$$
P_{t r}=\frac{M_{v}}{2 t_{a}}\left(V_{b}^{2}+V_{f}^{2}\right)+\frac{2}{3} M_{v} g f_{r} V_{f}+\frac{1}{5} \rho_{a} C_{D} A V_{f}^{3}
$$

In addition, it is necessary to consider the vehicle grade ability, which completely depends on the maximum tractive effort on the driven wheel as,

$$
F_{t}=M_{v} g\left(f_{r} \cos \alpha+\sin \alpha\right)+0.5 \rho_{a} C_{D} A V^{2}
$$

where $F_{\mathrm{t}}$ is the tractive effort on the driven wheels, and $\alpha$ is the road angle. For on-road vehicles, the tractive effort usually inherently meets the grade ability requirement when the power is satisfied with the acceleration performance. Take one $1500 \mathrm{~kg}$ vehicle for example. It only needs about $48 \mathrm{~kW}$ of tractive power on the road of $5^{0}$ grade $(8.75 \%)$ with the speed of $100 \mathrm{~km} / \mathrm{h}$, which is less than the tractive power $60 \mathrm{kw}$ required by the acceleration performance.

The simulation parameters in the PHEV system are supposed as follows: $M_{\mathrm{v}}=1567 \mathrm{~kg}, t_{\mathrm{a}}=10 \mathrm{~s}, \quad V_{\mathrm{f}}=100 \mathrm{~km} / \mathrm{h}$, $V_{\max }=200 \mathrm{~km} / \mathrm{h}, A=2.23 \mathrm{~m}^{2}, C_{\mathrm{D}}=0.26, f_{\mathrm{r}}=0.01$. Fig. 6 shows different resistance powers versus vehicle speed, where the rolling resistance power is in black dashed line and the aerodynamic one equals to the difference between red line and black line. From the diagram, the rolling resistance power plays the most important role resulting in $70 \%$ in the total resistance at $50 \mathrm{~km} / \mathrm{h}$. The higher the speed grows the more decisive becomes the exponentially increasing aerodynamic resistance. At $200 \mathrm{~km} / \mathrm{h}$ for example, the rolling resistance's ratio is already decreased to closely $14 \%$.

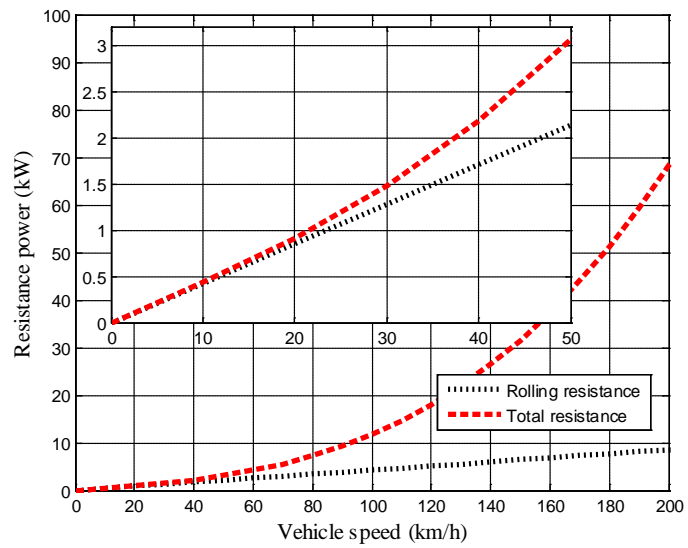

Fig. 6. Resistance power versus vehicle speed

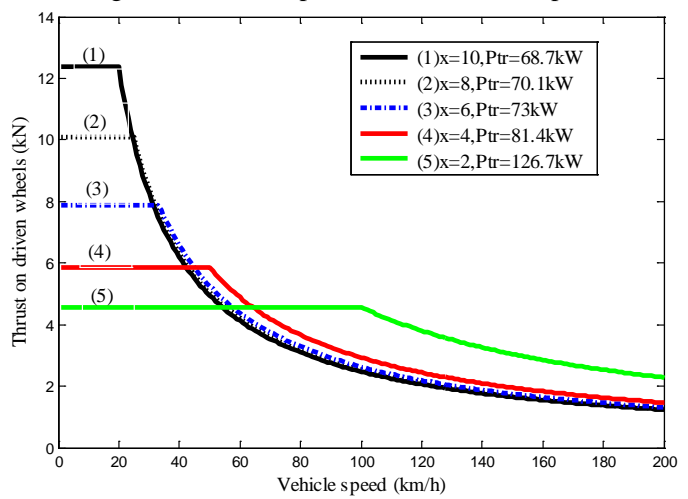

Fig. 7. Thrust and power versus vehicle speed 
The vehicle accelerates from zero to $100 \mathrm{~km} / \mathrm{h}$ in 10 seconds. Fig. 8 indicates that the time required for the same acceleration decreases with a large speed ratio $x$, that means a lower base speed. However, when the speed ratio $x$ is bigger than a certain value as illustrated in Fig. 8, for example 6, a small gain of power reduction can only gained by further increase of ratio $x$. Furthermore, the ratio $x$ is related closely with the drive machine type. In normal condition, the ratio $x$ in the system propelled by the switched reluctance machine can reach 6 , the inductance machine 4 , and the permanent magnet machine just only 2 .

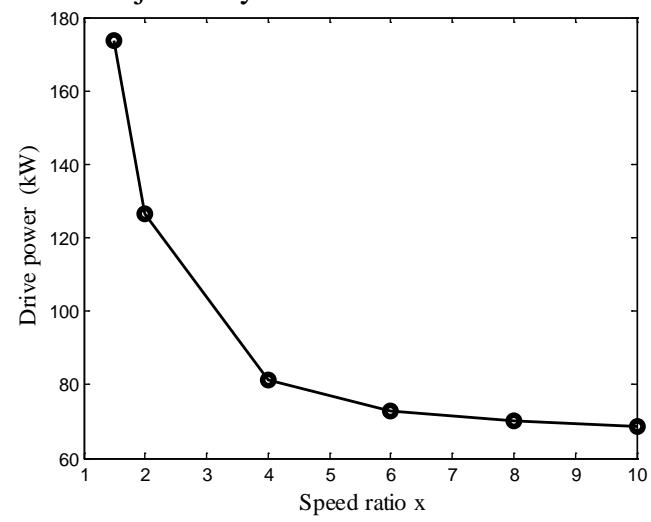

Fig. 8. Drive power versus speed ratio $x$

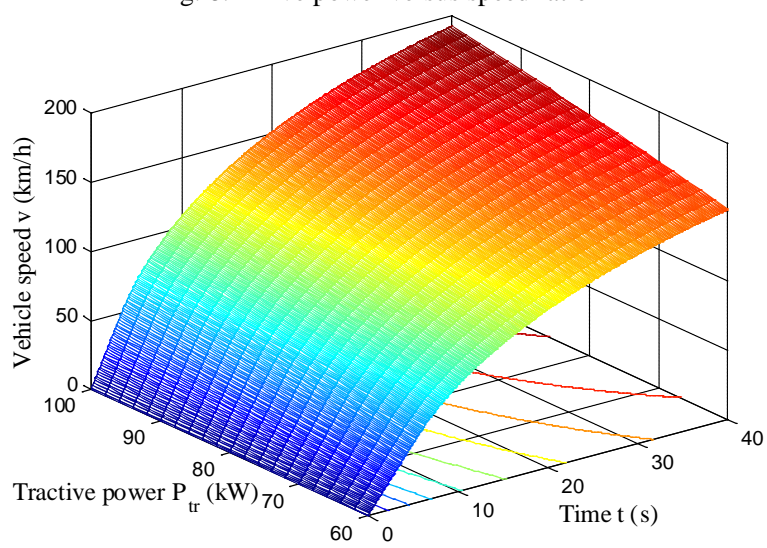

Fig. 9. Vehicle speed versus tractive power and time

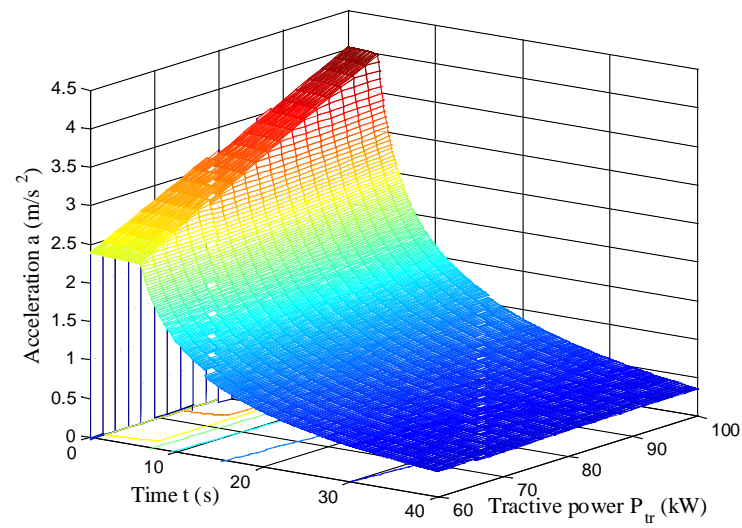

Fig. 10 Acceleration versus tractive power and time

The vehicle speed, acceleration and distance curves versus electric drive machine tractive power and time are shown in Figs.9-11 respectively. Different speed, acceleration and distance values can be gained when the machine power changes from 60 to $100 \mathrm{~kW}$, and the time from 0 to $40 \mathrm{~s}$. According to our initial project requirement, $80 \mathrm{~kW}$ tractive power can be chosen. In this condition, from 0 to $50 \mathrm{~km} / \mathrm{h}$ period, the time is $4.3 \mathrm{~s}$, the average acceleration is $3.2 \mathrm{~m} / \mathrm{s}^{2}$, and the distance is $29.8 \mathrm{~m}$; from 50 to $100 \mathrm{~km} / \mathrm{h}$ period, the time is $7.0 \mathrm{~s}$, the average acceleration is $1.8 \mathrm{~m} / \mathrm{s}^{2}$, and the distance is $150 \mathrm{~m}$.

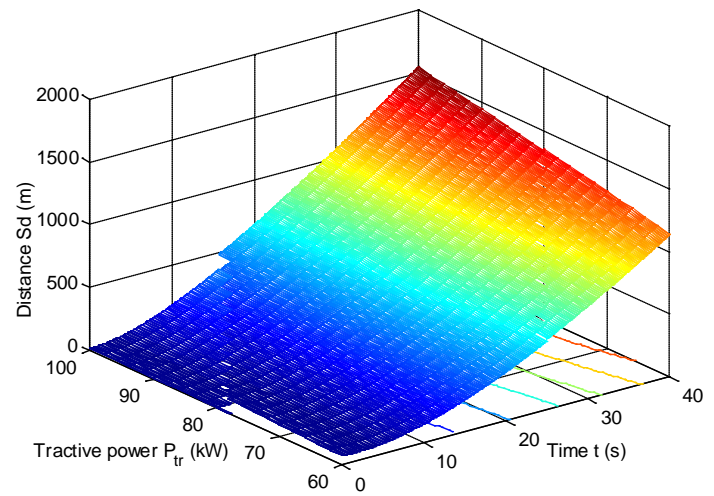

Fig. 11 Distance versus tractive power and time

\section{DRIVE SYSTEM PERFORMANCE ANALYSIS}

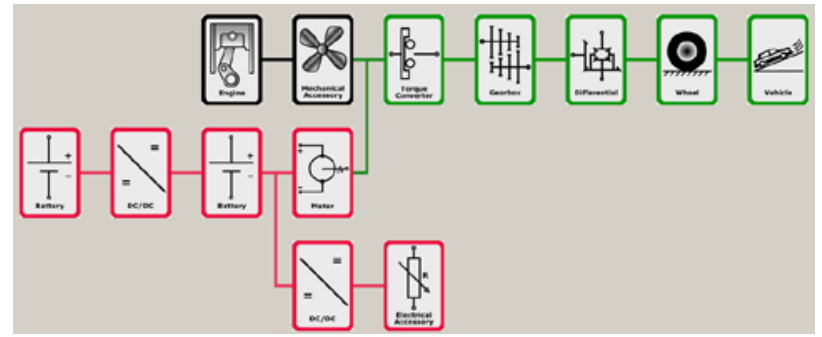

Fig. 12. Simulation model of the PHEV by PSAT

Based on the proposed vehicle parameters and the PHEV driving structure in Fig. 4, the propelling performance can be made by the powertrain system analysis toolkit (PSAT). This software has been developed by Argonne National Laboratory and sponsored by the U. S. Department of Energy (DOE)..It is modeled in MATLAB/Simulink environment and set up with a graphical user interface (GUI), which is friendly to users. Being a forward-looking model, PSAT allows users to simulate more than 200 predefined configurations, including conventional, pure electric, fuel cell, and hybrids (parallel, series, power split, series-parallel). The large library of component data enables users to simulate light, medium, and heavy-duty vehicles. By using test data measured at Argonne's Advanced Powertrain Research Facility, PSAT has been shown to predict the fuel economy of several hybrid vehicles within $5 \%$ on the combined cycle. It is the primier vehicle simulation package used to support the DOE FreedomCAR R\&D activities.

Fig. 12 is the PHEV simulation model by PSAT. It includes mainly mechanical accessory, clutch/torque converter, two energy storages involving battery and supercapacitor, drive motor, engine, et al.. There are three typical driving cycles applied in electric vehicle simulation, viz. urban 
dynamometer driving schedule (UDDS), extra-urban driving cycle (EUDC), and highway fuel economy driving schedule (HWFET). Their speed and acceleration profiles are shown in Fig. 13 and Fig.14 respectively.

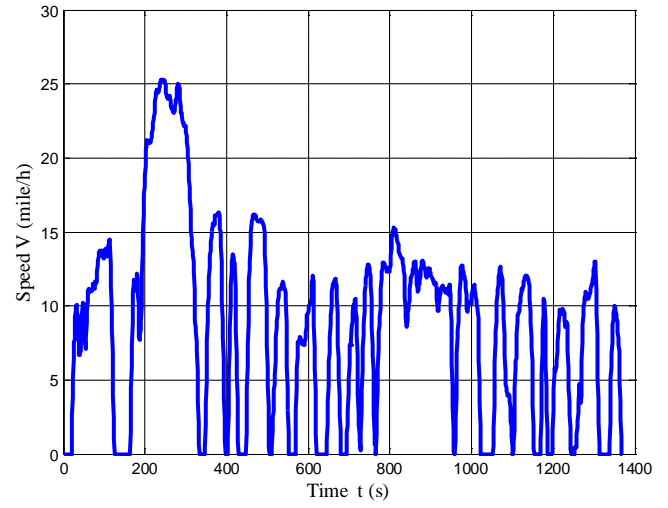

(a) UDDC driving cycle

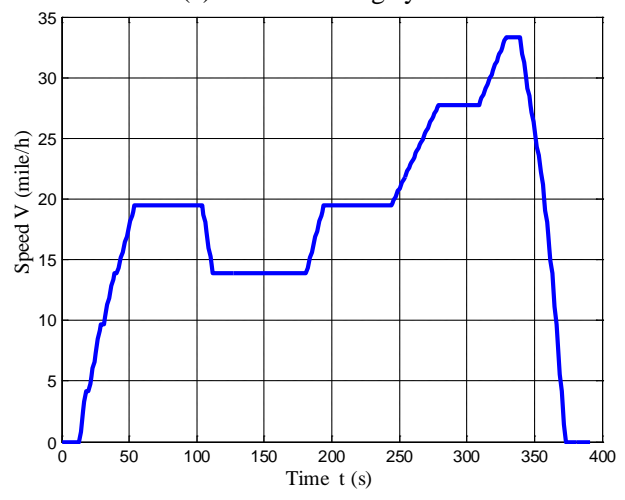

(b) EUDC driving cycle

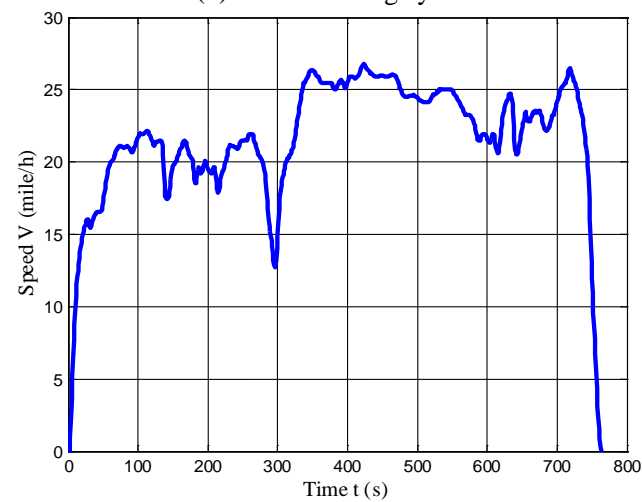

(c)HWFET driving cycle

Fig. 13. Speed profiles of three typical driving cycles

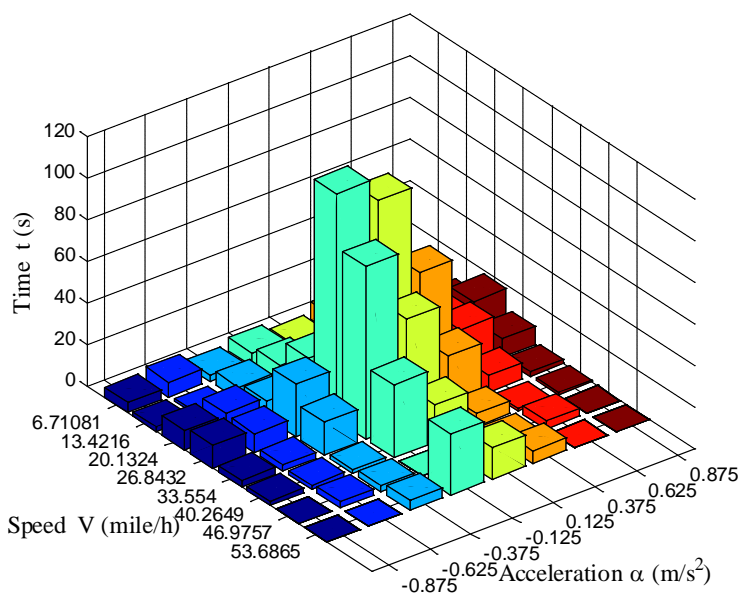

(a) UDDC driving cycle

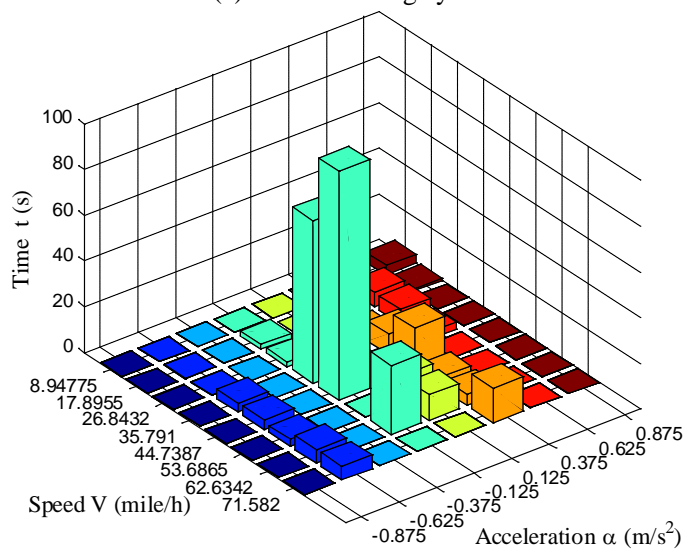

(b) EUDC driving cycle

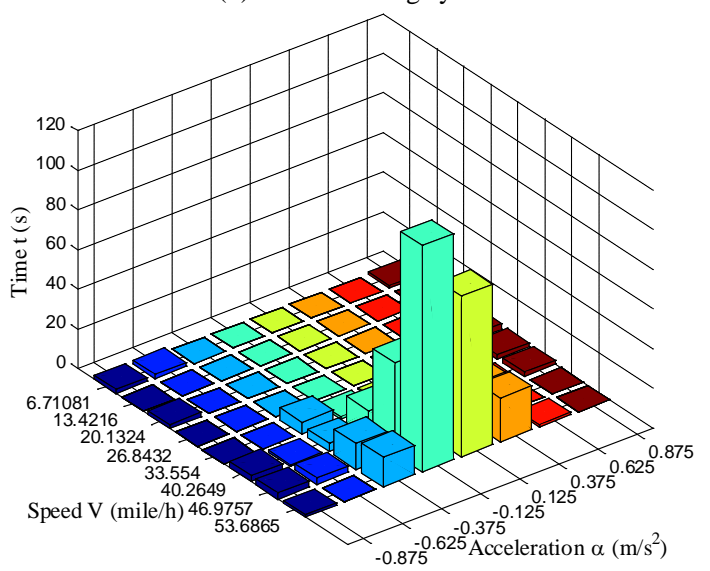

(c) HWFET driving cycle

Fig. 14. Acceleration profiles of three typical driving cycles

TABLE I. PERFormance COMPARISONS BETWEEN THE PHEV AND TRADITIONAL CAR

\begin{tabular}{|l|l|l|}
\hline Item & PHEV & Conventional \\
\hline Driving cycle & UDDS & UDDS \\
\hline Cycle distance (mile) & 9.68 & 7.42 \\
\hline Fuel economy (mile/gallon) & 70.91 & 33.92 \\
\hline Electric-only (Wh/mile) & 29.09 & - \\
\hline Engine efficiency (\%) & 28.15 & 27.89 \\
\hline Drive machine efficiency (\%) & 90.84 & - \\
\hline Mass of fuel needed to travel 320 miles (kg) & 14.26 & 26.75 \\
\hline Acceleration 0-60mile/h (s) & 21.1 & 14.7 \\
\hline
\end{tabular}




\begin{tabular}{|l|l|l|}
\hline Distance in (0-8)s (mile) & 0.05 & 0.06 \\
\hline Time to reach 0.25mile (s) & 22.2 & 20.5 \\
\hline Distance in (0-60)s (mile) & 0.62 & 0.71 \\
\hline
\end{tabular}

Table II. PERformance COMPARISONS OF THE PHEV THREE TyPICAL DRIVING CYCLES

\begin{tabular}{|l|l|l|l|}
\hline Item & UDDS & EUDC & HWFET \\
\hline Cycle distance (mile) & 9.68 & 4.64 & 10.39 \\
\hline Fuel economy (mile/gallon) & 70.91 & 48.63 & 37.91 \\
\hline Fuel consumption (gallon/100mile/ton) & 0.98 & 1.46 & 1.87 \\
\hline Mass of fuel to travel 320 miles (kg) & 13.93 & 20.80 & 26.68 \\
\hline Electric-only (Wh/mile) & 29.09 & 52.08 & 21.95 \\
\hline Engine efficiency (\%) & 28.15 & 34.63 & 36.83 \\
\hline Motor efficiency (\%) & 85.80 & 89.01 & 90.12 \\
\hline
\end{tabular}

Table I summarizes some performance comparisons between the PHEV and traditional car in UDDS driving cycle. Fuel economy in the PHEV has been improved to 70.91 mile/gallon, more than twice that of traditional one of 33.92 mile/gallon.

Table II shows the PHEV three-typical-driving-cycle performance. In the urban cycle, UDDS, the engine works at an efficiency of $28.15 \%$ and the fuel consumption is 0.98 gallon/100mile/ton, where the frequent accelerations and decelerations cycle shown in Fig. 13(a) cause this lower ICE efficiency. In the extra-urban cycle, EUDC, the speed range is slightly higher than in the urban one shown in Fig. 13(b) while the torque demand is increased due to the higher speeds. Consequently a higher ICE efficiency of $34.63 \%$ can be achieved, where the fuel consumption is increased to 1.46 gallon/100mile/ton. Best efficiency is achieved in the higher torque demanding highway cycle with $36.83 \%$ and a 1.87 gallon/100mile/ton fuel consumption. The conclusion is familiar with the results in [6].

Fig. 17 shows the electric machine torque-speed operating points in three typical driving cycles. The drive machine works below $200 \mathrm{rad} / \mathrm{s}$ for almost two-third cycle time in UDDS, and hence has the lowest efficiency of $85.80 \%$. By contrary, it operates above $200 \mathrm{rad} / \mathrm{s}$ for close three-fourth cycle time in HWFET which efficiency is $90.12 \%$. The EUDC has the medium efficiency of $89.01 \%$. Furthermore, the drive machine should have high power and torque densities with frequent starting and stopping, especially in the UDDC cycle.

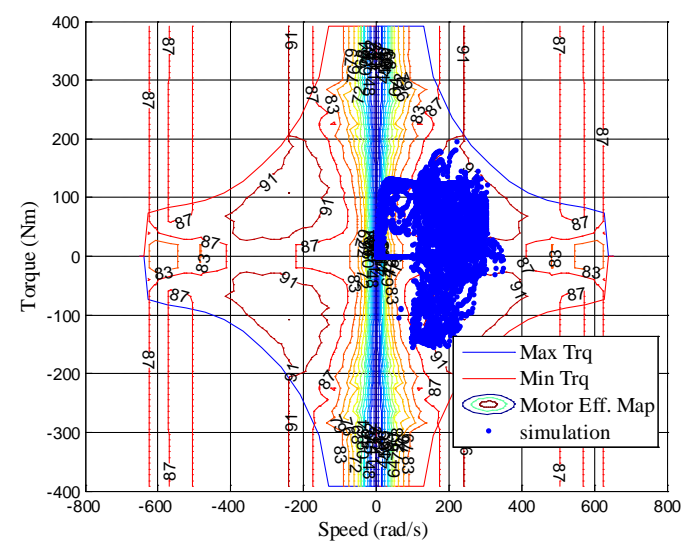

(a) UDDS

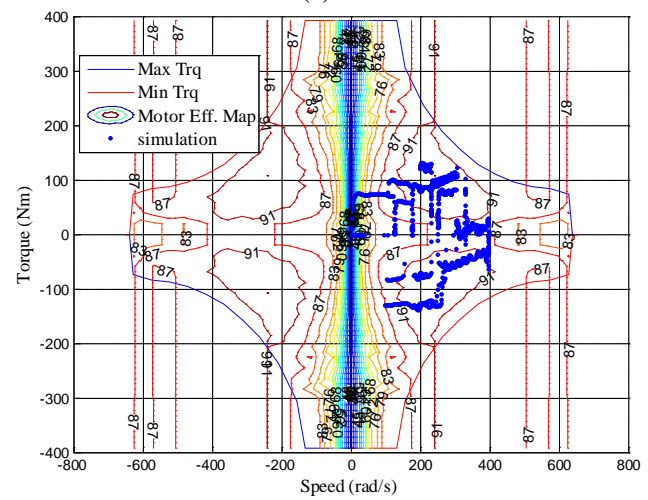

(b)EUDC

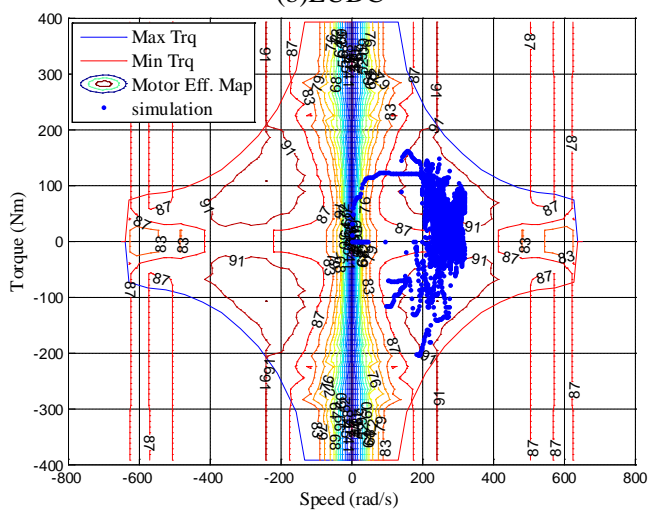

(c) HWFET

Fig. 15. Drive machine operating points in three driving cycles

\section{CONCLUSION}

HEVs have been paid much attention recently for their less emission to our air. This paper analyzes the merits and demerits of series, parallel, and combined parallel-series HEVs. Then it discusses the promising PHEVs in the near future for great development of battery technology. One novel PHEV structure has been investigated in this paper, which consists of only one electric machine that functions as a motor in normal drive or as a generator in braking or battery charging driven by the ICE. From drive system view, it analyzes rolling and aerodynamic resistance powers, and decides major propulsive parameters based on actual requirement. By the help of PSAT software, the PHEV drive performance in the UDDS cycle has been compared with that 
of traditional car. Moreover, the PHEV characterizations in three typical driving cycles, UDDS, EUDC, and HWFET, have been stuided comprehensively.

\section{REFERENCES}

[1] http://www.transportation.anl.gov/phev/.

[2] H. Oba, "Characteristics and analysis of efficiency of various hybrid systems,” Report of Toyota Motor Corporation, 2004, pp.935-957.

[3] http://avt.inel.gov/.

[4] S. A. Rahman, N. Zhang, and J.G. Zhu, "Modelling and simulation of an energy management system for plug-in hybrid electric vehicles," in Proc. Australasian University Power Engineering Conf.,2008.

[5] M. Ehsani, M., G. Yimin, et al, "Characterization of electric motor drives for traction applications," in Pro. IEEE Industrial Electronics Society Conf., 2003, pp.891-896.

[6] Tony Markel, "Plug-in hybrid-electric vehicles current status, long-term prospects and key challenges,” National Renewable Energy Laboratory report, Nov. 2006 